\begin{abstract}
Iranica
Abstracta Iranica Revue bibliographique pour le domaine irano-aryen

Volume 40-41 | 2019

Comptes rendus des publications de 2017-2018
\end{abstract}

\title{
Florence Jullien (éd.). Guerre et paix en monde iranien. Revisiter les lieux de rencontre
}

\section{Rédaction}

\section{(2) OpenEdition \\ 12 Journals}

\section{Édition électronique}

URL : http://journals.openedition.org/abstractairanica/50488

DOI : 10.4000/abstractairanica.50488

ISBN : 1961-960X

ISSN : 1961-960X

Éditeur :

CNRS (UMR 7528 Mondes iraniens et indiens), Éditions de l'IFRI

Référence électronique

Rédaction, "Florence Jullien (éd.). Guerre et paix en monde iranien. Revisiter les lieux de rencontre », Abstracta Iranica [En ligne], Volume 40-41 | 2019, document 3, mis en ligne le 30 décembre 2019, consulté le 20 avril 2021. URL : http://journals.openedition.org/abstractairanica/50488 ; DOI : https:// doi.org/10.4000/abstractairanica.50488

Ce document a été généré automatiquement le 20 avril 2021.

Tous droits réservés 


\title{
Florence Jullien (éd.). Guerre et paix en monde iranien. Revisiter les lieux de rencontre
}

\author{
Rédaction
}

\section{RÉFÉRENCE}

Florence Jullien (éd.). Guerre et paix en monde iranien. Revisiter les lieux de rencontre. (Studia iranica. Cahier 62), Paris, 2018, 299 p. ISBN 978-2-910640-48-4

1 Si la croyance, l'altérité ou les positionnements de pouvoir peuvent générer des actes de violence, en quoi peuvent-ils contribuer a contrario à endiguer la violence ? C'est en partie pour répondre à ce questionnement que cet ouvrage a été produit, fruit d'un programme de recherche conduit au sein du Laboratoire "Mondes iranien et indien" (UMR 7528) entre 2015 et 2017, et d'un cycle de conférences données dans le cadre du deuxième congrès du Groupement d'Intérêt Scientifique "Moyen-Orient et Mondes musulmans" à l'Institut national des langues orientales en juillet 2017. Il fait choix de rassembler une dizaine de contributions dans une dimension à la fois interdisciplinaire et diachronique, sur la longue durée : sur ce domaine aréal, sont mises en perspective des sources classiques ou contemporaines et des approches historiques, littéraires, géopolitiques, archéologiques, ethnologiques et anthropologiques, des perspectives d'histoire sociale et d'histoire des religions. Comme le souligne l'éditeur dans son avant-propos (p. 5-7), les différentes communautés des territoires composant le "monde iranien" ont certes souvent entretenu au cours des siècles des relations socioculturelles tendues entre replis identitaires, oppositions et exclusions; mais elles ont aussi largement contribué à tisser des échanges qui ont participé à la construction même des sociétés où elles étaient insérées.

2 Trois rubriques composent ce volume : 
3 1) « Violence et conciliation : pour une 'Realpolitik' », avec la collaboration de Wouter F. M. Henkelman, « Precarious gifts: Achaemenid estates and domains in times of war and peace» (p. 13-66), Christelle Jullien, "La piété du Perse "barbare". Modélisations chrétiennes en milieu sassanide» (p. 67-90) et Maria Szuppe, "Les "Nôtres" et les "Autres" dans la conquête qezelbāsh du Khorāsān : propagande et Realpolitik dans l'État safavide naissant » (p. 91-110).

2) "Affirmations communautaires entre échanges et antagonismes", avec la participation de Rika Gyselen, «Une cohésion culturelle par l'image? Le concept airterre-eau chez les artistes sassanides » (p. 113-128), Johnny Cheung, « Maintenir la paix religieuse entre les membres musulmans et yézidis des tribus kurdes» (p. 129-146), Florence Hellot-Bellier, «Violence et solidarités en Azerbaïdjan iranien avant et pendant la première guerre mondiale » (p. 147-176) et Anne-Sophie Vivier-Muresan, «Sanctuaires "partagés": lieux de tensions ou de rencontres?»(p. 177-196).

5 3) «Stratégies de gestion des conflits », avec les contributions de Florence Jullien, « Des chrétiens engagés pour la paix entre la Perse et Byzance. L'ambassade du catholicos Ǐšóyahb de Gdala » (p. 199-222), Denis V. Volkov, « War and Peace in the Other and the Self: Iran through the eyes of Russian spies. The case of Konstantin Smirnov (1877-1938) and Leonid Shebarshin (1935-2012)» (p. 223-258) et de Jean-Pierre Digard, « Meurtre, répression et réparation en milieu tribal iranien (Bakhtyâri, 1973-1974)» (p. 259-288).

Des index utiles des noms propres et des ethnonymes, ainsi que des toponymes, terminent cet ouvrage qui ouvre des pistes de réflexion sur des dialogues de cultures ayant contribué au façonnement du monde iranien, de l'Antiquité à nos jours.

\section{AUTEURS}

\section{RÉDACTION}

Direction et secrétariat d'Abstracta Iranica 